\title{
COMMUNICATION
}

\section{The Story of Ideals, Varieties and Algorithms}

\section{David A. Cox, John B. Little, and Donal O'Shea}

\author{
Communicated by Thomas Garrity
}

\section{Introduction}

Late in 2015 the three of us received an email from the American Mathematical Society notifying us that we had won the Leroy P. Steele Prize for Mathematical Exposition for our text Ideals, Varieties and Algorithms, published in 1992 and now in its fourth edition [4]. We were stunned. True, many readers over the years have told us that they loved the book. Nonetheless, the book was written for undergraduates, and to our knowledge no book written explicitly for undergraduates had ever won the Steele Prize.

We are often asked how the book got started, and we individually answer as best we can. When the Notices asked, we decided to pool our memories and offer the following account. With the advantage of over two decades of hindsight, we realize how much we owe to accident.

\section{The Serendipity of Location}

David arrived at Amherst College in 1979, Don at Mount Holyoke College in 1980, and John at Holy Cross in 1980. We are algebraic geometers, but at the time our research interests were quite different. Yet, well before we had ever dreamed of collaborating to write a book, we knew each other well. In retrospect, we realize that this happy accident was largely a function of location.

The magic was embodied in the Five Colleges, which comprise four liberal arts colleges (Amherst, Hampshire, Mount Holyoke, Smith) and the University of Massachusetts at Amherst. Although the institutions are very different, they are all within ten miles of each other, and students at any institution can take classes at any other. There are Five College mathematics seminars for faculty, well attended since we are roughly eighty-five

David A. Cox is professor of mathematics at Amherst College. His email address is dacox@amherst.edu.

John B. Little is professor of mathematics at College of the Holy Cross. His email address is $\mathrm{j} 1 \mathrm{i}$ tt $1 \mathrm{e} @$ ho 1 ycross . edu.

Donal B. O'Shea is president of New College of Florida. His email address is doshea@ncf. edu.

For permission to reprint this article, please contact:

reprint-permission@ams.org.

DOI: http://dx.doi.org/10.1090/noti1388

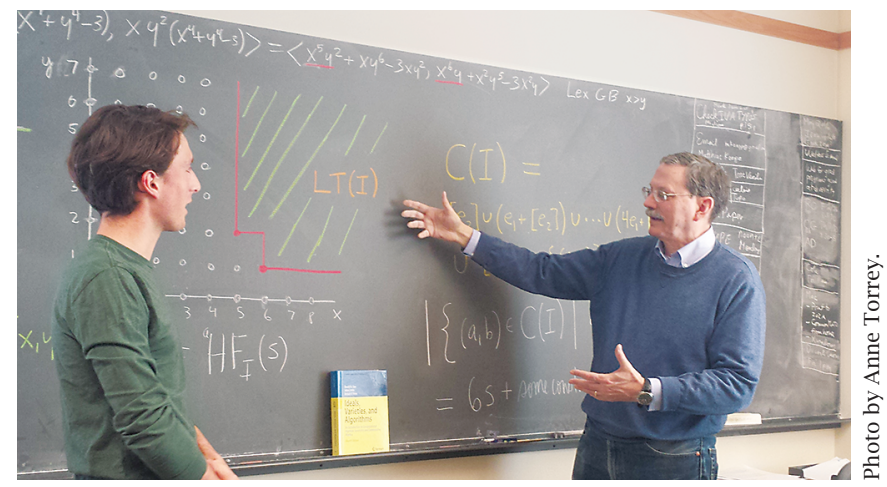

Cox talking with Amherst College senior Cole Hawkins about material from Ideals, Varieties and Algorithms that is related to the thesis he is writing on Betti diagrams.

miles west of the seminars in Boston. Our seminars also occasionally draw faculty from College of the Holy Cross in Worcester (fifty miles east), Keene State College (fifty miles north), and Williams College (fifty miles west).

As a result, the mathematics faculty members at our different institutions know each other in the same way that colleagues in a large department know one another. David and Don were frequently involved in organizing the seminars and would go out to dinner with the speakers, and John often came along. ${ }^{1}$ At dinner, we would not only talk about the seminar topic of the day but about our departments and the challenges of teaching undergraduates.

\section{The Serendipity of the Times}

Several things happened in the late 1980s that laid the groundwork for our book:

- In 1987 the NSF created the Research Experience for Undergraduates program.

\footnotetext{
${ }^{1}$ David first met John in 1974-75 when David was a visitor at Haverford College and John took courses that David taught on Galois theory and algebraic geometry.
} 
- At the same time, relatively small computers were getting powerful enough to do algebraic computations and graphics.

- In the summer of 1988 Don secured an REU grant for Mount Holyoke proposing that groups of undergraduates use computers to investigate examples that might shed light on current research questions. Don's group used the department's Sun 3/260 workstation to compute dimensions of finite-dimensional algebras associated with singular points of hypersurfaces in an attempt to find a counterexample to a question of Zariski.

- These computations rested on the theory of Gröbner bases developed by Bruno Buchberger in the 1960s [3]. By the mid-1980s computer implementations available in Macaulay [2] and REDUCE [6] enabled researchers to do substantial computations in algebraic geometry that went way beyond what was possible by hand. There was also GertMartin Greuel's Arbeitsgruppe at the University of Kaiserslautern, which focused on computational methods in singularity theory and algebraic geometry. The first versions of their program SINGULAR [5] were implemented around this time, and a rival group at the University of Genoa was working on the CoCoA project [1]. The field of computational algebraic geometry was being born.

- In 1988-89 Don was on sabbatical at Kaiserslautern as part of Greuel's group, learning this wonderful mathematics. Meanwhile, David was back in Amherst, blissfully unaware. And unbeknownst to both of them, John already knew much of it, having learned about what came to be known as Gröbner bases from interactions with Mike Stillman and Dave Bayer, the creators of Macaulay, as a result of the year he spent at Harvard in 1979-80.

- In the late 1980s, the Pew Charitable Trusts created NECUSE, the New England Consortium for Undergraduate Science Education, to foster collaborative projects aimed at improving and enriching undergraduate education in science. In September 1988, NECUSE announced support for the development of curricula for new advanced undergraduate mathematics courses.

All of the pieces were now in place-all we needed was a wacky idea.

\section{The Birth of the Book}

The exciting developments in Kaiserslautern and elsewhere were taking place at a very high level, involving top flight researchers and their graduate students. During his first semester in Kaiserslautern, Don was inspired by his REU experience from the previous summer to write to David with the idea of turning this Gröbner basis stuff into something suitable for undergraduates. Don volunteered to write a grant proposal to support the project.

In January 1989 Don wrote a grant entitled "Computational Algebraic Geometry and Commutative Algebra"

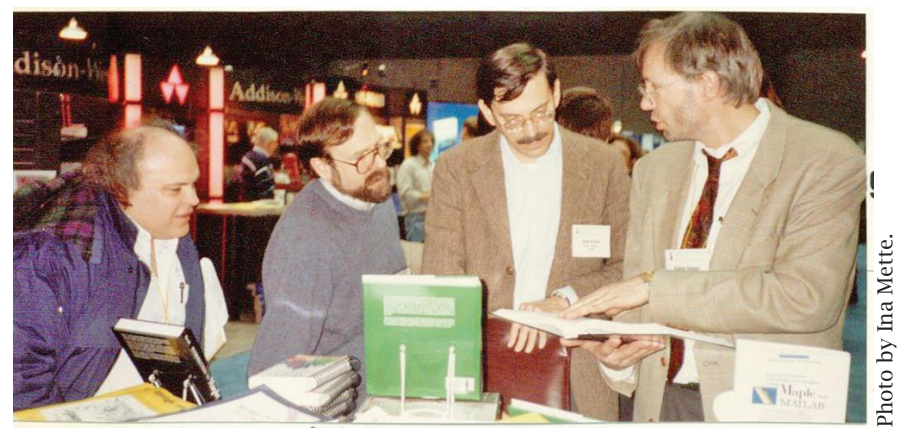

Donal O'Shea, John B. Little, and David A. Cox with Springer's Rüdiger Gebauer at the Joint Mathematics Meetings in Cincinnati in 1994.

that would eventually total US\$60,000 from NECUSE. At that time, NECUSE wanted people from small colleges to collaborate with people from research universities, so Don's first draft listed the personnel as Don, David, and "Person X." However, the university people we asked were understandably busy with the research demanded by their positions, so we had no takers. Back in Amherst, David went to dinner after a seminar and aired his frustrations. John, who was in town for the seminar, said quietly, "I know this stuff." This is when two became three, and the book was born.

\section{The Writing of the Book}

We did not propose to write a textbook; rather, the original concept of the project was to create a set of "modules" that could be used to supplement the standard undergraduate abstract algebra course. We wrote the first three modules and a draft of the fourth in the summer of 1989. In the course of revising these modules during the following year it became natural to call them "chapters."

We were firmly committed to making the material truly accessible to undergraduates. As a first step, this meant settling prerequisites. We wanted to include detailed proofs and debated the level of sophistication that we could assume of students. At our different institutions we had different levels of rigor in the courses we taught, particularly in the linear algebra course. David suggested that we should assume that students have a solid course in linear algebra, together with a course such as discrete mathematics that did proofs. In particular, we decided not to require that readers had taken a course in abstract algebra. In retrospect, this also helped make the book more understandable for readers outside mathematics.

One reason this material is accessible to undergraduates and nonmathematicians is that pictures can be used to give vivid illustrations of the theory. For example, consider the family of circles of radius 1 whose centers lie on the parabola $y=x^{2}$, as shown in the figure at the top of the next page. The "outline" of this diagram, called its envelope, has an equation that can be found by Gröbner basis methods available in programs such as Maple ${ }^{\mathrm{TM}}$ or Mathematica ${ }^{\circledR}$. Something interesting is happening in the dark region of the picture, leading to a discussion of the singularities of the envelope, which can be computed 
explicitly. Armed with examples like this, teaching and learning algebraic geometry becomes a lot of fun.

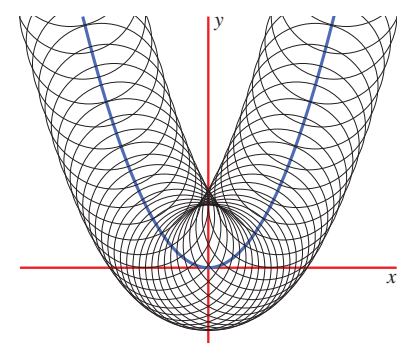

The text also included a fair number of algorithms, and we went back and forth on whether to include actual code or pseudocode. John argued for the latter and prevailed. Given how rapidly computer algebra systems have evolved and changed over the years, this proved to be a wise decision.

The initial grant from NECUSE provided money for the computers (Sun workstations and IBM 386 desktop computers) we used to compute examples for the text. By late 1990 we were up to five "chapters" and finally realized that we were writing a book! We were able to get further funds from NECUSE to support the writing of the rest of the book, now titled Ideals, Varieties and Algorithms following a suggestion from David. The NECUSE funds also enabled us to send numerous copies of the manuscript to people at other institutions. The feedback we got was extremely helpful as we worked to finish the book. We also taught courses at Amherst and Holy Cross using draft versions of the text.

\section{Getting a Publisher}

One striking thing about Ideals, Varieties and Algorithms is that there was no natural place for it in the undergraduate curriculum. This had the potential to limit its sales, which could lead a publisher to set a high price for the book. Yet we were determined to keep the price low. We had submitted the book to several publishers. One Saturday morning in 1991, David received a call from Rüdiger Gebauer at Springer-Verlag New York (now Springer), urging that we publish with them. Besides making a good offer regarding price and marketing, there was another bit of serendipity: before joining Springer, Rüdiger was one of the authors of the REDUCE Gröbner basis package [6] that David used in writing the book. Rüdiger really understood what we were trying to accomplish. This is part of why we published with Springer.

\section{Conclusion}

Shortly after receiving the AMS email about the Steele Prize, David wrote to Don and John saying that "collaborating with the two of you has been one of the greatest pleasures of my professional life." He voiced what we each felt. The book arose from a wonderful confluence of many things. We have enjoyed this opportunity to piece together the story of how Ideals, Varieties and Algorithms came to be.

\section{References}

[1] J. АввотT, A. M. Bigatti AND G. LAgOrio, CoCoA-5: A system for doing computations in commutative algebra, available at cocoa.dima.unige.it.

[2] D. BAYER and M. STILlman, The design of Macaulay: a system for computing in algebraic geometry and commutative algebra, in SYMSAC '86 Proceedings of the Fifth ACM Symposium on Symbolic and Algebraic Computation, Association for Computing Machinery, New York, 1986, pp. 157-162. Macaulay's successor is Macaulay 2 [7].

[3] B. BUCHBERGER, Ein algorithmus zum auffinden der basiselemente des restklassenrings nach einem nulldimensionalen polynomideal, doctoral thesis, Mathematical Institute, University of Innsbruck, 1965. English translation: "An algorithm for finding the basis elements of the residue class ring of a zero dimensional polynomial ideal" by M. P. Abramson, J. Symb. Comput. 41 (2006), 475-511. MR 2202562

[4] D. A. Cox, J. B. LitTle and D. O'SheA, Ideals, Varieties and Algorithms: An Introduction to Computational Algebraic Geometry and Commutative Algebra, Fourth Edition, Undergraduates Texts In Mathematics, Springer, New York, 2015. MR 3330490

[5] W. Decker, G.-M. Greuel, G. Pfister, and H. SchönemanN, SINGULAR-A computer algebra system for polynomial computations, available at http://www. singular.uni-k1.de.

[6] R. Gebauer and H. M. MöLler, On an installation of Buchberger's algorithm, J. Symb. Comput. 6 (1988), 275-286. MR 0988418

[7] D. R. GRAYSON and M. E. STILlman, Macaulay2, a software system for research in algebraic geometry, available at www. math.uiuc.edu/Macaulay2/.

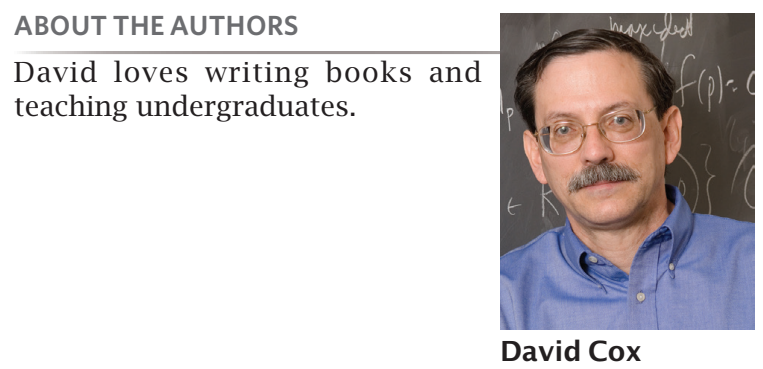

John plays the viola and is learning ancient Greek.

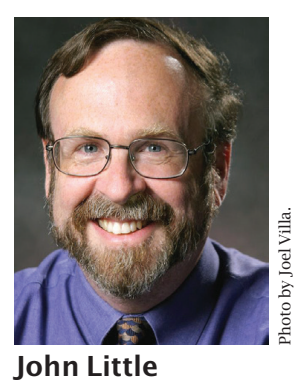

Although Donal crossed to what some consider the dark side two decades ago, he still identifies primarily as a mathematician and a teacher.

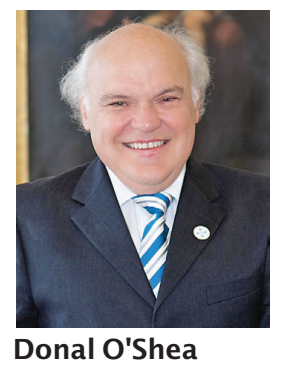

